$2015-12$

\title{
Agroecological, climatic, land elevation and socio-economic determinants of pesticide use at the farm level in Bangladesh
}

Rahman, Sanzidur

http://hdl.handle.net/10026.1/3776

10.1016/j.agee.2015.07.002

Agriculture, Ecosystems \&amp; Environment

Elsevier BV

All content in PEARL is protected by copyright law. Author manuscripts are made available in accordance with publisher policies. Please cite only the published version using the details provided on the item record or document. In the absence of an open licence (e.g. Creative Commons), permissions for further reuse of content should be sought from the publisher or author. 
Manuscript ID: AGEE13175

Revised version incorporating comments of the referees and the editor Agriculture, Ecosystems and Environment 212 (2015) 187-197

Agroecological, climatic, land elevation and socio-economic determinants of pesticide use at the farm level in Bangladesh Sanzidur Rahman*

School of Geography, Earth and Environmental Sciences, University of Plymouth, Drake Circus, Plymouth PL4 8AA, UK

$\underline{\text { Address for correspondence }}$

Dr. Sanzidur Rahman

Associate Professor in Rural Development

School of Geography, Earth and Environmental Sciences

University of Plymouth

Drake Circus

Plymouth, PL4 8AA

Phone: $+44-1752-585911$

Fax: $+44-1752-584710$

E-mail: srahman@plymouth.ac.uk 


\title{
Agroecological, Climatic, Land Elevation and Socio-economic Determinants of Pesticide
}

\section{Use at the Farm Level in Bangladesh}

\author{
ABSTRACT
}

This study examines the influence of agroecology, climate, land elevation and socio-economic factors on pesticide use at the farm level using a large survey data of 2083 farms from 17 districts covering 10 agroecological zones in Bangladesh by applying a Tobit model. Overall, 75.4\% of farmers used pesticides in any one crop. Within the pesticide users, pesticide use rate is highest in oilseed production estimated at BDT $2508.6 \mathrm{ha}^{-1}$ (3.74\% of gross output value) followed by jute at BDT $1976.1 \mathrm{ha}^{-1}(1.88 \%$ of gross output value). Pesticide use is significantly lower in floodplain agroecologies, high rainfall areas, high land and low land elevation zones but significantly higher in medium high land elevation zone. Among the socio-economic factors, pulse area significantly reduces pesticide use whereas an increase in rice and pulse prices and organic manure application significantly increases it. Educated farmers and medium/large as well as small farms use significantly more pesticides. Policy implications include investments in developing crop varieties suitable for floodplain agroecologies, high rainfall, high land and low land elevation zones, expansion of pulse area and a reduction in fertilizer prices.

KEY WORDS: Pesticide use, multivariate Tobit analysis, agroecology, climate, land elevation, Bangladesh.

\section{Introduction}

Although pesticide application is supposed to be a damage control measure in preventing production loss from pest and/or disease attacks and is not a yield enhancing input, there is a widespread acceptance that the expansion of modern agricultural technologies has led to a sharp increase in pesticide use (Rahman, 2013, 2003a; Pingali and Rola, 1995). Pesticide is also 
believed to improve nutritional value of food and its use is viewed as an economic, labour-saving and efficient tool for pest management (Damalas and Eleftherohorinos, 2011). Furthermore, pesticide is believed to bring about competitive advantage for agricultural crops (Delcour et al., 2015). Pesticide use is growing continuously worldwide both in numbers and quantities since the 1940s. The total pesticide production has increased from one million metric ton (mmt) in 1965 to nearly 6 mmt in 2005 (Carvalho, 2006) despite widespread claim of its adverse effects, e.g., emergence of pest resistance and harm to human health and the environment ( $\mathrm{Hou}$ and $\mathrm{Wu}$, 2010; Pimentel, 2005; Pingali, 1995; Antle and Pingali, 1994). This is because pesticide use is seen as a necessity to retain the current production and yield levels and maintain high quality and standard of life (Delcour et al., 2015). It is predicted that pesticide use by farmers in developing countries will continue mainly due to: (a) an ignorance of the sustainability of pesticide use; (b) a lack of alternatives to pesticides; (c) an underestimation of the cost of pesticide use both in the short- and the long-run; and (d) the weak enforcement of laws and regulations governing pesticide use (Wilson and Tisdell, 2001). Furthermore, pesticide efficiency and use can also be influenced by environmental conditions. It is expected that with climate change, pesticide use will also be affected leading to more pesticide application by farmers due to increased vulnerability to pests and diseases as well as reduction in pest residues in crops (Delcour et al., 2015).

Bangladesh is a country most vulnerable to climate change and, therefore, is susceptible to the range of effects outlined above including vulnerability to pests and diseases. This is because most food crops are sensitive to direct effects of high temperature and extreme precipitation as well as indirect effects of climate on soil properties, nutrients and pest organisms (Rosenzweig et al., 2001). Pesticide use in Bangladesh, negligible until the 1970s, has recorded a 
dramatic rise over the past few decades. For example, pesticide use was only $0.26 \mathrm{~kg}$ of active ingredients per ha in 1977 but increased to $1.23 \mathrm{~kg}$ in 2002 (Rahman, 2010). In fact, pesticide use grew at an alarming rate of $10.0 \%$ per year during the period 1977-2009 although the corresponding response in yield growth of major crops has been minimal $(<1.0 \%$ per year). As a result, pesticide productivity (i.e., 'gross value added from crops at constant prices' per 'kg of active ingredients of all pesticides used') is declining steadily at a rate of $-8.6 \%$ per year during 1977-2009 (Rahman, 2013).

A limited number of studies are available which examined socio-economic determinants of pesticide use at the farm level in Bangladesh (e.g., Dasgupta et al., 2005; Mahmoud and Shively, 2004; Rahman, 2003a; Rahman and Hossain, 2003; Hossain et al., 1999). Although these studies provide valuable information on socio-economic factors influencing pesticide use, none of them considered the influence of the production environment and climate within which farming operations occur when identifying the determinants of pesticide use. This is because farmers' production performance does not only depend on the physical resources and technology available to them, but also on the existing environmental production conditions (Rahman and Hasan, 2008). In fact, pesticide efficiency, crop characteristics, pest occurrence and severity are directly influenced by climate (Delcour et al., 2015), and therefore, likely to influence pesticide use. Sherlund et al. (2002) and Rahman and Hasan (2008) noted that ignoring variables representing environmental production conditions in the models leads to biased parameter estimates. Both studies demonstrated that taking account of environmental production conditions significantly improved farmers' technical efficiency of input pesticide use for rice in Cote d'Ivoire (Sherlund et al., 2002) and wheat in Bangladesh (Rahman and Hasan, 2008). Specifically, pest infestation was found to be significantly positively correlated to area 
cultivated, mechanical power services, irrigation, herbicide use and organic manure (Rahman and Hasan, 2008) and child labour and fertilizers (Sherlund et al., 2002).

Given this backdrop, the present study examines the influence of agroecology, climate, land elevation, and a range of price and socio-economic factors on pesticide use at the farm level in Bangladesh using a recently conducted large survey data of 2,083 farm households from 17 districts (or 20 sub-districts) of Bangladesh spread over 10 agroecological zones (AEZs). Our specific contribution to the existing literature is that we have incorporated a wide range of variables representing the production environment and climate within which farming operations occur as explanatory factors of pesticide use at the farm level which is previously non-existent. Incorporation of these variables will not only establish their direction and magnitude of influence on pesticide use but also provide a more accurate and unbiased estimates of all the parameters of the model as noted by Rahman and Hasan (2008) and Sherlund et al. (2002).

The paper is organised as follows. Section 2 presents description of the study areas, the data, analytical framework and the empirical model. Section 3 presents the results. Section 4 provides conclusions and draws policy implications.

\section{Methodology}

\subsection{The study areas and the data}

Bangladesh has a total of 64 districts and 486 sub-districts (BBS, 2013). Data for this study was taken from a recently completed NFPCSP-FAO Phase II project (Kazal et al., 2013). The data was collected during February-May 2012 through an extensive farm-survey in 17 districts covering 20 sub-districts (upazillas) of Bangladesh. A multistage sampling technique with mixture of purposive and stratified random sampling methods was employed. At the first stage, districts where the specified crops are dominant are selected purposively. The selection of the 
districts also took into account specified characteristics, i.e., land elevation types of the region and type of technology. At the second stage, sub-districts were selected according to highest concentration of these specified crops in terms of area cultivated based on information from the district offices of the Directorate of Agricultural Extension (DAE). At the third stage, unions were selected using same criteria at the union/block level which was obtained from the subdistrict offices of the DAE. Finally, the farmers were selected using a stratified random sampling procedure from the villages of the selected unions with three standard farm size categories (commonly used in Bangladesh) as the strata. These are: marginal farms (farm size 50-100 decimals), small farms (101-250 decimals), and medium/large farms ( $>250$ decimals). To ensure equal representation of all farm size categories, a target of 105 farmers from each sub-district was set as follows: 35 marginal farms, 35 small farms, and 35 medium/large farms. This provided a total of 2,083 farm households (Table 1). The questionnaire used was pre-tested in Tangail district prior to finalization. The questionnaire included detailed information on demographic characteristics including age, gender, occupation and education of individual members of the households, land ownership including tenurial status and detailed information on the crops produced and inputs used including pesticides in the production of individual crops. The survey was conducted using face to face interviews with the farmers and was carried out by trained enumerators who were graduate students of the Sher-e-Bangla Agricultural University, Dhaka and/or Bangladesh Agricultural University, Mymensingh (for details, see Kazal et al., 2013).

\subsection{Theoretical framework}

The study utilizes a farm production model based on profit maximizing behaviour of the farmers adopted by Rahman (2003a) and extends it further by incorporating variables representing 
production environment and climate using the approach adopted by Rahman and Hasan (2008) and Sherlund et al. (2002).

We begin by specifying a model with two variable input vectors: pesticides, $H$ and 'other inputs', $X$, and one fixed input of land, $L$ to produce $\mathrm{n}$ number of crops $(i=1 \ldots n)$ where $\mathrm{L}_{\mathrm{i}}$ is land area allocated to the $i^{\text {th }}$ crop.

Farmer $j$ maximizes total profits:

$\sum_{i=1}^{n} p_{i} Q_{i j}-w^{Q} H_{j}-w^{O} X_{j}$

s.t. $Q_{i j}=f\left(H_{i j}, X_{i j}, L_{i j}, S_{j}, E_{j}\right)$ for $i=1 \ldots . n$

and $\sum_{i=1}^{n} L_{i j} \leq L_{j}$

where $H_{j}=H_{l j}+\ldots .+H_{n j}$

and $\quad X_{j}=X_{l j}+\ldots .+X_{n j}$

Equation (1) is an individual production function for each crop $i$. The production function Q depends on pesticide (H) applied to that crop, 'other variable inputs (X's)' applied to that crop, land (L) allocated to that crop, and a set of exogenous socio-economic variables $\left(S_{j}\right)$ and another set of exogenous variables $\left(E_{j}\right)$ representing environmental production conditions that shift the production function. Equation (2) simply states that land allocated to various crops must be equal or less than the total land cultivated by the producer.

The first order conditions lead to the corresponding demand functions for pesticides and 'other inputs' for individual crops:

$Q_{j}=Q_{j}\left(w^{Q}, w^{O}, p_{1} \ldots p_{n}, L_{1 j} \ldots, L_{n j}, S_{j}, E_{j}\right)$

$O_{j}=O_{j}\left(w^{Q}, w^{O}, p_{1} \ldots p_{n}, L_{l j} \ldots, L_{n j}, S_{j}, E_{j}\right)$

where p's and w's are output and input prices, respectively. 
We can aggregate the pesticide demand functions of individual crops as follows:

$$
Q_{j}{ }_{j}=Q^{\prime}{ }_{j}\left(w^{Q}, w^{O}, p_{1} \ldots p_{n}, L_{1 j} \ldots, L_{n j}, S_{j}, E_{j}\right)
$$

The assumption of the separability of inputs (pesticide on one hand, and all 'other inputs' on the other) enables the pesticide demand equation to be estimated separately ${ }^{1}$. Observe that the arguments appearing in the aggregate pesticide demand function are the vector of input prices, output prices, and a set of exogenous factors.

\subsection{The empirical model}

Since not all farmers use pesticides in their production process (see Table 2), the application of Ordinary Least Squares regression will result in biased and inconsistent estimates because the dependent variable is censored at zero. The Tobit model provides a suitable method for estimating the pesticide demand equation in this case, as it allows for zero use of inputs (e.g., Rahman, 2003a).

The stochastic model underlying Tobit may be expressed as follows:

$Q_{j}^{\prime}{ }^{*}=Q_{j}^{\prime} *\left(\left(w^{Q}, w^{O}, p_{1} \ldots p_{n}, L_{1 j} \ldots, L_{n j}, S_{j}, E_{j}\right)+u_{j}\right.$

$Q_{j}^{\prime}{ }^{*}$ is a latent variable such that:

$\begin{aligned} Q_{j}^{\prime} & =Q_{j}^{\prime} * & & \text { if } Q_{j}^{\prime}>0 \\ & =0 & & Q_{j}^{\prime} \leq 0, \quad j=1,2, \ldots \ldots m\end{aligned}$

where the disturbances $u_{j}$ is an error term and is independent and identically distributed as $\mathrm{N}(0$, $\left.\sigma^{2}\right)$

\section{$2.4 \quad$ Variables}

\footnotetext{
${ }^{1}$ Individual estimation of factor demand functions utilizing separability assumption has been widely used in empirical studies (e.g., Rahman, 2003a).
} 
The amount of pesticide used per hectare $\left(\mathrm{BDT} \mathrm{ha}^{-1}\right)$ was specified as the dependent variable in the econometric model. This is because, although the survey included questions to report pesticide quantity and the total value of pesticide used in individual crops separately, the farmers could recall only the amount of money spent for pesticides for each individual crops under investigation. The main reason farmers could not provide information on actual quantity of pesticides applied because generally farmers tend to buy pesticides in bottles without reading specification or net weight of the active ingredients in the bottle, which may be due to either a lack of interest or illiteracy. Since we do not have actual quantity of pesticides used, we are unable to include own price variable (i.e., pesticide price) as one of the regressors in the model, although inverse relationship exists between pesticide price and the quantity of its use (e.g., Rahman, 2003a).

\subsubsection{Explanatory variables: Input and output prices and other socio-economic factors}

The list of variables included in the pesticide demand function was: (a) input prices - prices of urea, Triple Super Phosphate (TSP), Muriate of Potash (MP), Diammonium Phosphate (DAP), and gypsum fertilizers, labour wage and land rent (imputed for owned land); (b) output prices weighted average of prices of all varieties of rice, weighted average of prices of wheat and maize, jute price, pulse price and oilseed price; (c) amount of land allocated to various crops in hectares - crops include all varieties of rice combined, wheat and maize combined, jute, pulse, and oilseed; (d) a set of socio-economic characteristics which include average age of the farmer, average education of the farmer, use of organic manure per ha, average family size of the household, dummy variables to represent farm size category (i.e., marginal or small or medium/large farms) and a dummy variable to account for membership in NGOs). Information on the amount of credit and/or non-agricultural income could not be included in the model 
because the survey did not collect information on these variables, although these variables potentially influence pesticide use. For example, Rahman (2003a) noted significantly positive influence of credit on pesticide use. Table 4 presents the definition, measurement and summary statistics of all the variables used in the econometric model.

\subsubsection{Explanatory variables: Variable representing agroecology, land elevation and climate}

An attempt has been made to construct explanatory variables to represent agroecological characteristics, land elevation and climate within which actual agricultural production takes place. The variables are defined and constructed as follows:

\begin{tabular}{|c|c|}
\hline $\begin{array}{l}\text { Agroecological } \\
\text { characteristics }\end{array}$ & $\begin{array}{l}\text { Bangladesh consists of } 30 \text { agroecological zones (AEZ) constructed } \\
\text { by FAO in } 1988 \text { which overlaps amongst administrative boundaries, } \\
\text { thereby, making regional classification very difficult. However, } \\
\text { Quddus (2009) conducted an exercise by combining two or three } \\
\text { AEZs together so that the new classification commensurate with } \\
\text { district administrative boundaries. The result was } 12 \text { composite } \\
\text { AEZs derived from original } 30 \text { AEZs that can be distributed into } 64 \\
\text { new districts and are mutually exclusive (for details, see Table } 1 \text { in } \\
\text { Quddus, 2009). We have created a set of seven dummy variables to } \\
\text { represent these composite AEZs (which actually covers } 10 \text { of the } \\
\text { original } 30 \text { AEZs) covering our sampled } 17 \text { districts and allocated } \\
\text { them as appropriate. }\end{array}$ \\
\hline Land elevation & $\begin{array}{l}\text { The Bangladesh Agricultural Research Council (BARC) created a } \\
\text { database of area and proportion of major land elevation types in } \\
\text { each of the } 30 \mathrm{AEZs} \text { (BARC, undated). The land elevation data in }\end{array}$ \\
\hline
\end{tabular}




\begin{tabular}{|c|c|}
\hline & $\begin{array}{l}\text { Bangladesh is classified according to flooding depth of the } \\
\text { landscape. These are: High Land (i.e., no flooding); Medium High } \\
\text { Land (flooding depth of } 0.10-0.90 \mathrm{~m} \text { ); Medium Low Land (flooding } \\
\text { depth of } 0.91-1.83 \mathrm{~m} \text { ); Low Land (flooding depth of }>1,83 \mathrm{~m} \text { ). We } \\
\text { have used this information and constructed a complete set of the } \\
\text { proportion of High Land, Medium High Land, Medium Low Land } \\
\text { and Low Land for each of the seven composite AEZ that are } \\
\text { relevant for our } 17 \text { sampled districts (BARC, undated). }\end{array}$ \\
\hline Total rainfall & $\begin{array}{l}\text { Total rainfall measured in mm for each greater district per month } \\
\text { from a list of rainfall recording stations is available from the } \\
\text { Bangladesh Meteorological Department. The allocation of this } \\
\text { rainfall information is made depending on the location of the } \\
\text { rainfall station. We compute the sum of } 12 \text { monthly rainfall data for } \\
\text { the year 2012 for each district as a measure of total annual rainfall } \\
\text { (BBS, 2013) }\end{array}$ \\
\hline Temperature variability & $\begin{array}{l}\text { Monthly maximum temperature is also available for each greater } \\
\text { district from Bangladesh Meteorological Department). We } \\
\text { computed standard deviation of the monthly maximum temperature } \\
\text { for the year } 2012 \text { for each district as a measure of temperature } \\
\text { variability (BBS, 2013). }\end{array}$ \\
\hline
\end{tabular}

Fertilizers (various types), labour and animal power are the major inputs in crop 212 production and contribute significantly to the production costs. Farmers seeking to maximize 
profits are expected to respond to input price changes and adjust their input use accordingly (Rahman, 2003b). Therefore, prices of various fertilizers, labour wage and animal power price are included in the pesticide demand function. Similarly, prices of crops produced have a direct bearing on the profit generated from farming and farmers are expected to respond to changes in the crop prices to choose their cropping portfolio. Therefore, prices of crops produced are included in the pesticide demand function.

We have also included organic manure application in order to identify its independent influence on pesticide use. This is because farmers are increasingly using organic manure in order to enhance/conserve soil fertility as well as economise on the use of inorganic fertilizers in farming (Rahman and Hasan, 2008). However, use of organic manure may itself attract pests which will have a bearing on farmers' pesticide demand.

Farmers allocate different amount of land to individual crop on the farm. Since different crops have different types and frequencies of pest infestation (Rahman, 2003a), the areas allocated to individual crops are incorporated to determine their independent influences on pesticide use.

Farm size was found to have significant influence on pesticide use (Rahman, 2003a). However, it is not clear which farm size categories use more pesticides. In Bangladesh, average farm size is declining consistently and the proportion of marginal and small farms are rising (Rahman 2010). Therefore, we have included dummy variables to capture the individual influence of small and medium/large farms on pesticide demand. The influence of the marginal farms is subsumed in the intercept/constant term.

Use of age and education level of farmer as explanatory variables is common in the literature (Rahman, 2009). These variables, acting as a group or separately, are expected to have 
an influence on pesticide demand in the following ways. For instance, education is used as a surrogate for a number of factors. At the technical level, access to information as well as capacity to understand the technical aspects related to farming may influence crop choices and hence pesticide use. Age of the farmer is incorporated to account for the maturity of the farmer in his/her decision-making ability related to pesticide use.

Family size is included in the pesticide demand function for two reasons. First, according to Chayanovian theory, higher subsistence pressure (measured by family size) generally leads to adoption of modern technologies which may in turn lead to increased use of pesticide. On the other hand, large family size may also imply supply of more family labour which may influence pesticide use, either positively or adversely.

Climate change has been one of the hottest debates and Bangladesh is earmarked as the country most vulnerable to climate change. Therefore, two climate variables: total annual rainfall and variability in maximum monthly temperature were included to identify their independent influences on pesticide use. This is because pest infestation is influenced by high rainfall and temperature extremes (Delcour et al., 2015) which in turn will influence pesticide use.

Similarly, agroecological characteristics is another important feature that either limits or opens up opportunities for farmers to choose their cropping portfolio and hence pesticide use which remains largely ignored in the literature. A total of six dummy variables representing agroecological characteristics (or AEZs) were incorporated in the model to identify their independent influence on pesticide use, leaving the remaining $7^{\text {th }}$ AEZ subsumed in the intercept/constant term.

Finally, land elevation (measured with respect to flooding depth) is also an important feature that is expected to influence farmers' crop choice decisions and hence pesticide use. This 
is because not all crops are suited to all types of land elevation. For example, most of the rice crops in Bangladesh are suited for medium high land zones and deep water Aman rice is a unique crop suited for flooded or submerged land and is cultivated mostly in ox-bow lake (haor) and/or low lying areas of the country. Therefore, we have included variables representing proportions of high land, medium high land, and low/very low land zones available at the AEZ level to identify their influence on pesticide use. However, because of the coexistence of all three categories of land elevation in each AEZ in variable proportions, the proportion of area under high land elevation is significantly negatively correlated with the remaining three categories $(\mathrm{r} \geq$ $-0.98, \mathrm{p}<0.01)$. Therefore, in order to break multicollinearity, we have executed four separate models by replacing one land elevation category at a time, while retaining all other variables.

\section{RESULTS}

\subsection{Pesticide use rates in crops}

Use of pesticides in crops is dependent upon pest infestations and prevalence of diseases and the type of crops grown (Rahman, 2003a). Table 2 presents information on the extent and magnitude of pesticide use in different crops. It is surprising to see that highest proportion of the maize farmers $(86.6 \%)$ have used pesticides followed by HYV Boro rice $(68.0 \%)$ and wheat producers $(61.1 \%)$. In contrast, only $12.0 \%$ of the jute farmers used pesticides although it is a major cash crop of the economy. Overall $75.4 \%$ of the farmers have used pesticides in any one crop at least. Chakrabarty et al. (2014) and Bhattacharjee et al. (2013) reported that $50.0 \%$ and $63.2 \%$ of the rice farmers applied pesticides whereas Rahman (2003a) noted a figure of $77.3 \%$ of the farmers using pesticides in any one crop at least in 1996. Although these figures are not strictly comparable, it seems that almost similar proportion of farmers are using pesticides at present compared to 16 years ago when multiple crop production is considered. 
Within the pesticide users of each individual crop, Table 2 shows that the highest rate of pesticide use is in oilseed (BDT 2508.6 ha ${ }^{-1}$ ) followed by jute (BDT $1976.1 \mathrm{ha}^{-1}$ ) and aromatic rice (BDT 1599.6 ha ${ }^{-1}$ ). The overall pesticide use rate is BDT $1090.5 \mathrm{ha}^{-1}$. When examined in terms of factor shares of production, pesticide cost share was found to be highest for oilseed (3.7\% of the gross value of production) followed by aromatic rice ( $2.5 \%$ of gross value) and jute (1.9\% of gross value). The overall factor share of pesticide use is estimated at $1.4 \%$ of gross value of output which is very close to $1.5 \%$ of gross value in 1996 as reported by Rahman (2003a).

Table 3 presents information on the extent and magnitude of pesticide use by farm size categories. Although the proportion of farmers using pesticides is almost identical between marginal and small farm size categories estimated at $74.7 \%$ and $74.9 \%$ of total farmers, respectively, a slightly higher proportion of medium/large farmers use pesticides $(76.5 \%$ of total farmers). However, when pesticide use rate is considered, Table 3 shows that the marginal farms use lowest level of pesticides per ha estimated at BDT 1025.5 whereas the use rate is higher and very similar between small and medium/large farm categories.

In order to investigate whether farmers are overusing pesticides, as noted by Dasgupta et al. (2005), we compared our pesticide use rates presented in Table 2 with information presented in Table A1 in the appendix. Table A1 presents information on the most popular pesticides used by Bangladeshi farmers on the crops under consideration along with their recommended dose per ha, application frequency and current market price. If we cost the recommended dose of pesticides per ha with their current market price (i.e., last column of Table A1) and compare that information with the information presented in Table 2, we see that the sampled farmers are using 
pesticides roughly close to the recommended doses for the crops except oilseeds, where the application rate by the farmers are substantially higher than the recommended level.

\subsection{Socio-economic and agroecological characteristics of the study areas}

The basic information on the socio-economic characteristics and agrocology, climate and land elevation features of the study areas is presented in Table 4. Farming system is dominated by cereals (rice and wheat) as reflected by average area allocated to these crops as compared with non-cereal crops. The average age of the farmers is 44.8 years, average education level is just above primary level (i.e., 5.6 completed years of schooling) and average family size is 5.0 persons.

Among the agroecological features, $25 \%$ of the sampled farms belong to composite AEZ comprising of Karatoa Floodplain and Atrai Basin (KFAB) zones followed by $22 \%$ from another composite AEZ comprising of Old Himalayan Piedmont Plain and Tista Floodplain (HPTF) zones. The main soil types of KFAB are grey, silt-loam and silt-clay loam and HPTF are sandy loam, loamy and silt clay loam (Quddus, 2009). The fertility conditions of KFAB are moderate to medium and organic material levels are low medium to medium levels. On the other hand, fertility conditions of HPTF are low to medium and organic material levels are low to good levels (Quddus, 2009). With respect to the distribution of land elevation types, we find that the highest land elevation category is medium high land covering an average of $39 \%$ of the total land area of the 10 sampled AEZs which is characterized by a flooding depth of 0.01 to $0.9 \mathrm{~m}$ and is most suitable for farming. This is followed by high land elevation category covering an average of $30 \%$ of the total land area which is characterized by no flooding but also not strictly suitable for all types of farming in general (Table 4). The average total rainfall in the study areas is $1707.9 \mathrm{~mm}$ and the variability in monthly maximum temperature is $3.96{ }^{\circ} \mathrm{C}$. 


\subsection{Determinants of pesticide use}

Table 6 presents the parameter estimates of the pesticide demand function. Prior to reporting the results, we report a series of hypothesis tests conducted to justify inclusion of these diverse set of regressors in the pesticide demand model (Table 5). The first test is to confirm whether the full model including full range of environment and climate variables is superior to the model without these variables. The null hypothesis of no superiority $\left(\mathrm{H}_{0}:\right.$ All $\left.\kappa_{\mathrm{i}}=0\right)$ is strongly rejected at $1 \%$ level. Next a series of tests were conducted to check individual influences of prices and socioeconomic factors on pesticide demand which are strongly rejected at $5 \%$ level at least. Finally, the individual influence of agroecological, climatic and land elevation features are also strongly rejected at $1 \%$ level of significance (Table 5).

Since, parameters of the Tobit model cannot directly reveal the magnitude of the effect, we compute elasticities and presented in column 5 of Table 6 which show responsiveness of a one percent change in the relevant variable on the probability of pesticide use except for the dummy variables where it measures the responsiveness of a discrete change from zero to unity. Among the output prices, pesticide demand is significantly influenced by a rise in pulse and rice prices. The influence of the price of pulse is highly elastic estimated at 2.79 indicating that a one percent increase in pulse price will increase the probability of pesticide use by $2.79 \%$. Rahman (2003a) also reported significant influence of a rise in pulse price on pesticide demand which remains valid even today. This is because relative profitability of pulse is still very low as compared with other non-cereals. Therefore, a rise in pulse price will induce farmers to use pesticide in order to increase yield. This is because the use rate of pesticide in pulse is still the lowest, same as observed by Rahman (2003a) 16 years ago. 
Farmers treat pesticides as substitutes for labor and phosphate fertilizer (highly elastic response estimated at 2.64) but as complements of urea and gypsum fertilizers. This finding partly conforms to Rahman (2003a) who aggregated all fertilizers into one category and reported substitution relationship between fertilizers and pesticides. Since we have separated each fertilizer type, we see that only phosphate fertilizer is treated as substitute. This is because the price of fertilizer is on the rise in Bangladesh. For example, the price of phosphate fertilizer has doubled from only BDT $7.00 \mathrm{~kg}^{-1}$ in 1999 to BDT $15.00 \mathrm{~kg}^{-1}$ in 2007 (Mujeri et al., 2012). Therefore, the effect of a rise in the price of fertilizer will induce incremental use of pesticides. Similarly, labor wage is also on the rise in Bangladesh. For example, the index of real agricultural labor wage has increased more than three folds from 1870.00 in 1997/98 to 6133.58 in $2011 / 12$ (Base year 1969/70 = 100) $(B B S, 2013)$. Therefore, an increase in labor wage will induce farmers to use more pesticides to save on intercultural operation cost of labor. However, an increase in pulse area significantly reduces pesticide demand which can also be implied from Table 2 as use rate of pesticide is lowest in pulse. Use of organic manure significantly increases pesticide demand. This may be due to the fact that application of organic manure (which is mostly raw cow dung) increases pest infestation, thereby, leading to more pesticide use.

Educated farmers use significantly more pesticides. However Rahman (2003a) and Dasgupta et al (2005) did not find any significant influence of education on pesticide use. Both medium/large and small farms use significantly more pesticides relative to marginal farms which conform to the findings of Rahman (2003a) who reported pesticide use increases with farm size although Dasgupta et al (2005) did not find any influence of farm size on overuse of pesticides.

Coming to our variables of interest, we see that pesticide use is significantly lower in floodplain agroecologies relative to Sylhet Basin and Surma-Kushiyara Floodplain which is 
actually at a high level of elevation in the hilly region of the country and its own effect is subsumed in the intercept term. All responses are in the elastic range except for Ganges Tidal Floodplain zone.

Pesticide use is significantly higher in the medium high land elevation (which is the most suitable landscape for farming) and the response is in the elastic range (elasticity value 1.13) whereas it is significantly lower for high land and very low or low land elevation zones ${ }^{2}$ with highly elastic response for the latter (elasticity value -2.4 ). The implication is that the low lying areas which are more prone to flooding have lower incidence of pest and disease infestations and hence requires less use of pesticides. Similarly, high land areas which are not prone to flooding at all but probably attract less pest and disease infestations and therefore require less use of pesticides.

Among the climatic factors, pesticide use is significantly lower in high rainfall areas and the responsiveness is the highest of all in the model with elasticity value estimated at -6.8 . The implication is that pest attack and prevalence of disease are lowest in wet areas and, therefore, subsequent use of pesticide is very low.

Since no other studies explicitly considered environmental and climatic factors in determining pesticide demand, we cannot provide any comparison of our findings within the context of the literature. Although, Dasgupta et al. (2005) and Rahman (2003a) controlled for

\footnotetext{
${ }^{2}$ As mentioned at the end of section 2.4.2 that these land elevation variables are significantly negatively correlated amongst themselves, we have modelled four separate regressions by including one land elevation variable at a time. Table 6 presents the results of the model with medium high land included in the equation. The influence of other three categories of land elevation variables are from three independent regression models and are presented in parentheses. It is worth noting that general results of all other models are almost identical to the one reported model in Table 6 and hence not presented.
} 
district level effects and concluded that pesticide use is significantly influenced by regional characteristics, we believe that controlling for environment and climate are more accurate and meaningful as these factors directly affect the production conditions within which farmers operate whereas district is an arbitrary administrative unit.

\section{Conclusions and policy implications}

The principal aim of this study is to explicitly identify the influence and magnitude of the environment and climate, within which farming operation occurs, on pesticide use which is nonexistent in the literature. Specifically, we have included a number of variables representing agroecology, climate and land elevation features in addition to other usual price and socioeconomic factors in the econometric model to determine their individual influences on the demand for pesticides based on a large sample of 2,083 farms from 17 districts (20 sub-districts) spread over 10 out of a total of 30 agroecological zones of Bangladesh.

Although the overall proportion of farmers applying pesticides (75.4\% of total sample) seems to be similar to the one reported in the literature 16 years ago (i.e., $77.3 \%$ reported by Rahman, 2003a), we find that highest proportion of maize producers are applying pesticides $(86.6 \%)$ instead of cereal (i.e., rice and wheat) producers as conventionally believed. Also, the use rate and factor share of pesticide was highest for oilseed followed interchangeably by jute and aromatic rice, all of which are cash crops. The implication is that a boost in the production of these three crops, which are suitable for export to earn foreign exchange, will lead to an increase in pesticide use. For example, the value of export of jute and its products, oilseeds (with oleaginous fruits) and rice is estimated at BDT 22,373.9, BDT 348.6 and BDT 34.9 million, respectively in 2011/12 (BBS, 2013). 
The key findings of this study are the establishment of the fact that the environment and

climate significantly influence pesticide use in variable ways. Specifically, pesticide use is significantly lower in floodplain agroecologies, high rainfall areas and high land as well as low land elevation zones but significantly higher in medium high land zones. Moreover, the magnitude of the influences of these variables is largely in the elastic range which means that a one percent change in these variables will lead to a larger proportional change in the probability of pesticide use.

Farmers treat pesticides as substitutes for labor and phosphate fertilizer but as complements of urea and gypsum fertilizers. The implication is that a rise in labor wage (which is a desired goal for supporting landless and marginal farmers through the hired labor market as wage laborer) will induce a significant rise in pesticide use mainly to reduce the amount of labor for various farm operations, particularly intercultural operations. Similarly, a rise in the price of urea (which is the most common fertilizer applied by farmers in cereals) will induce a significant increase in pesticide use. The prices of all fertilizers are on the rise in Bangladesh following the liberalization of the fertilizer market and removal of subsidy since 1992 (Rahman, 2003a). But the government is reverting to control prices indirectly by facilitating distribution of urea fertilizer in recent years, which will have a favorable impact on reducing pesticide use. For example, the total amount of fertilizer subsidy in Bangladesh has increased from BDT 1.0 billion in $2001 / 02$ to BDT 29.1 billion in $2009 / 10$ (in constant $2001 / 02$ prices) and $87 \%$ of the total subsidy was for urea fertilizer alone (Mujeri et al., 2012).

On the other hand, increases in rice and pulse prices (which are again desirable for boosting revenue/profit for the farmers) would lead to a significant increase on pesticide use although the marginal effect is much higher for an increase in pulse price. Nevertheless, since 
actual pesticide use rate in pulse crop is lowest and small (Table 2), the magnitude of increase in pesticide use in response to a rise in pulse price will not be very large. However, it is encouraging to note that an increase in the area under pulse (which is a soil fixing leguminous crop contributing to soil conservation) will induce a significant reduction in pesticide use.

The overall policy implications of this study are clear. Bangladesh needs to develop varieties of cereal and non-cereal crops suitable for floodplain agroecologies, high rainfall areas, high land and low land elevation zones which will synergistically reduce pesticide use. In other words, $R \& D$ investments should be geared towards developing crop varieties which thrive in rainfed conditions over a prolonged period instead of relying on supplementary irrigation as with the case of high yielding varieties of rice. Also to develop varieties of crops that can withstand submergence and/or flooding. At present only deep water Aman rice is available which rises in response to rises in water depth and is the most popular crop in ox-bow lakes and low lying areas of Bangladesh. Finally, Bangladesh need to develop crop varieties suitable for high land elevation (which is apparently characterized with slopes or undulated terrains) which ideally should be low water requiring in nature, e.g., wheat. It is important to emphasize that the existing research extension linkage in Bangladesh is very weak and needs to be strengthened substantially so that the new technologies developed in the research stations (e.g., those mentioned here) reaches the farmers in time (Rahman and Hasan, 2008). Also, price policies aimed at reducing prices of all fertilizers in general and an expansion of pulse area are highly desirable as these will synergistically reduce pesticide use significantly. In fact, we emphasize a reduction in the prices of all fertilizers and not only urea so that the imbalance in fertilizer use, which led to a dramatic rise in the use of urea only (Mujeri et al., 2012), is curbed and also improve yield of crops. 

reduction in pesticide use is important to sustain the agricultural sector as well as safeguard the farming population, which is a goal worth pursuing.

\section{Acknowledgements}

The database required for this project was created with the financial support from Seale-Hayne Educational Trust, UK (2011) and National Food Policy Capacity Strengthening Program (NFPCSP), FAO-Bangladesh Competitive Research Grant, Phase II (2011). The author gratefully acknowledges critical comments of the anonymous referees and the editor which has improved the manuscript substantially. However, all caveats remain with the author. 
Antle, J.M., Pingali, P.L., 1994. Pesticides, productivity and farmer health: a Philippine case study. American Journal of Agricultural Economics ,76: 418-430.

Bangladesh Bank, 2013. Economic Trends (monthly publications) 2013. Dhaka: Bangladesh Bank.

BARC, undated. Climate and LRI database. Bangladesh Agricultural Research Council. Available@ @ http://www.barcapps.gov.bd/dbs/index.php?t=land du. Accessed December 05, 2014.

BBS, 2013. Statistical Yearbook of Bangladesh, 2012. Dhaka: Bangladesh Bureau of Statistics.

Bhattacharjee, S., Chowdhury, M.A.Z., Fakhruddin, A.N.M., Alam, M.K. 2013. Impacts of Pesticide Exposure on Paddy Farmers' Health. Jahangirnagar University Environmental Bulletin, 2: 18-25.

Carvalho, F.P. 2006. Agriculture, pesticides, food security and food safety. Environmental Science and Policy, 9:685-92.

Chakrabarty, Y., Akter S., Saifullah, A.S.M., Sheikh, M.S., Bhowmick, A.C. 2014. Use of Fertilizer and Pesticide for Crop Production in Agrarian Area of Tangail District, Bangladesh. Environment and Ecology Research, 2: 253-261.

Damalas, C.A., Eleftherohorinos, I.G. 2011. Pesticide exposure, safety issues, and risk assessment indicators. International Journal Environmental Research and Public Health, 8: 1402-19.

Dasgupta, S., Meisner, C., Huq, M. 2005. Health effects and pesticide perception as determinants of pesticide use: evidence from Bangladesh. Washington, DC: The World Bank Policy Research Working Paper \#3776. 
Delcour, I., Spanoghe, P., Uyttendaele, M. 2015. Literature review: Impact of climate change on pesticide use. Food Research International, 68: 7-15.

Hossain, M.I., Shively, G., Mahmoud, C. 1999. Factors influencing pesticide use in ricevegetable farming system in Bangladesh. Bangladesh Journal of Agricultural Economics, 22: 87-98.

Hou, B., Wu, L. 2010. Safety impact and farmer awareness of pesticide residues. Food and Agricultural Immunology, 21:191-200.

Kazal, M.M.H., Rahman, S., Alam, M.J., Hossain, S.T. 2013. Financial and economic profitability of selected agricultural crops in Bangladesh. NFPCSP-FAO Research Grant Report \#05/11. Dhaka, Bangladesh. July 2013.

Mahmoud, C., Shively, G. 2004. Agricultural diversification and integrated pest management in Bangladesh. Agricultural Economics, 30: 187-94.

Mujeri, M.K., Shahana, S., Chowdhury, T.T., Haider, K.T. 2012. Improving the effectiveness, efficiency and sustainability of fertilizer use in South Asia. Global Development Network, New Delhi, India.

Pimentel, D. 2005. Environmental and socio economic costs of the applications of pesticides primarily in the United States. Environment, Development and Sustainability, 7:229-52.

Pingali, P.L., 1995. Impact of pesticides on farmer health and the rice environment: an overview of results from a multidisciplinary study in the Philippines. In Pingali PL, Roger P, (Eds) Impact of Pesticides on Farmer Health and the Rice Environment. Boston: Kluwer Academic Publishers. p. 3-22. 
Pingali, P.L., Rola, A.C. 1995. Public regulatory roles in developing markets: the case of Philippines. In Pingali P.L., Roger P, (Eds) Impact of Pesticides on Farmer Health and the Rice Environment. Boston: Kluwer Academic Publishers. p. 391-411.

Quddus, M.A. 2009. Crop production growth in different agro-ecological zones of Bangladesh. Journal of Bangladesh Agricultural University, 7: 351-360.

Rahman, S. 2003a. Farm-level pesticide use in Bangladesh: determinants and awareness. Agriculture, Ecosystem and the Environment, 95: 241-52.

Rahman, S. 2003b. Profit efficiency among Bangladeshi rice farmers. Food Policy. 28: 487-504.

Rahman, S. 2009. Whether crop diversification is a desired strategy for agricultural growth in Bangladesh. Food Policy, 34: 340-349.

Rahman, S. 2010. Six decades of agricultural land use change in Bangladesh: Effects on crop diversity, productivity, food availability and the environment, 1948-2006. Singapore Journal of Tropical Geography, 31: 254-269.

Rahman, S. 2013. Pesticide consumption and productivity and the potential of IPM in Bangladesh. The Science of the Total Environment. 445-446: 48-56.

Rahman, S., Hasan, M.K. 2008. Impact of environmental production conditions on productivity and efficiency: a case study of wheat farmers in Bangladesh. Journal of Environmental Management. 88: 1495-1504.

Rahman, S., Hossain, M.Z. 2003. Pesticide demand in hybrid seed production technology. Journal of Food, Agriculture and the Environment, 1:174-179.

Rosenzweig, C., Iglesias, A., Yang, X, Epstein, P.R., Chivian, E. 2001. Climate change and extreme weather events: implications for food production, plant diseases, and pests. Global Change and Human Health, 2: 90-104. 
Sherlund, S.M., Barrett, C.B., Adesina, A.A. 2002. Smallholder technical efficiency controlling for environmental production conditions. Journal of Development Economics, 69: 85 101.

Wilson, C, Tisdell, C. 2001. Why farmers continue to use pesticides despite environmental, health and sustainability costs? Ecological Economics, 39: 449-62. 
Table 1. Distribution of sample according to farm type by districts

\begin{tabular}{llcccc}
\hline \multicolumn{1}{c}{ District } & Sub-district & \multicolumn{3}{c}{ Farm Type } \\
\cline { 3 - 6 } & & Marginal & Small & $\begin{array}{c}\text { Medium / } \\
\text { Large }\end{array}$ & $\begin{array}{c}\text { Total surveyed } \\
\text { Farms }\end{array}$ \\
\hline Tangail & Mirzapur & 35 & 35 & 35 & 105 \\
Mymensingh & Phulpur & 34 & 36 & 35 & 105 \\
Kishoreganj & Karimganj & 35 & 35 & 35 & 105 \\
Netrokona & Khaliajuri & 21 & 38 & 46 & 105 \\
Faridpur & Bhanga & 35 & 35 & 35 & 105 \\
& Boalmari & 20 & 20 & 20 & 60 \\
Rajshahi & Charghat & 35 & 35 & 35 & 105 \\
Natore & Lalpur & 34 & 35 & 36 & 105 \\
Sirajganj & Ullapara & 35 & 35 & 35 & 105 \\
Bogra & Sherpur & 31 & 34 & 33 & 98 \\
& Sariakandi & 35 & 35 & 35 & 105 \\
Jaipurhat & Kalai & 35 & 35 & 35 & 105 \\
Dinajpur & Chirirbander & 36 & 30 & 39 & 105 \\
& Birganj & 70 & 35 & 35 & 140 \\
Thakurgaon & Balia Dangi & 35 & 35 & 35 & 105 \\
Lalmonirhat & Hatibandha & 34 & 34 & 37 & 105 \\
Barisal & Bakerganj & 35 & 35 & 35 & 105 \\
Kushtia & Sader & 35 & 35 & 35 & 105 \\
Sunamganj & Derai & 35 & 35 & 35 & 105 \\
Habiganj & Baniachang & 31 & 38 & 36 & 105 \\
& Total & 696 & 685 & 702 & 2083 \\
\hline
\end{tabular}


Table 2. Pesticide use rates and its factor share in gross value of output for different crops.

Crops $\begin{array}{r}\text { \% of farmers using } \\ \text { pesticides in specific }\end{array}$
pesticides in specific Pesticide use rate (BDT Pesticide cost share as gross

\begin{tabular}{lrrr} 
& crops & ha $^{-1}$ ) & value of output (\%) \\
\hline Boro rice & 67.99 & 1476.83 & 1.46 \\
Aman rice & 58.51 & 1182.56 & 1.58 \\
Aromatic rice & 58.08 & 1599.61 & 2.53 \\
Wheat & 61.12 & 1045.97 & 1.69 \\
Maize & 86.60 & 1158.17 & 1.41 \\
Jute & 11.95 & 1976.11 & 1.88 \\
Pulse & 39.22 & 596.30 & 0.78 \\
Oilseed & 49.76 & 2508.59 & 3.74 \\
All crops & 75.37 & 1090.53 & 1.40 \\
Note: Total number of observations is 3905 comprising of 1306 Boro rice, 911 Aman rice, 167 aromatic rice, 553 \\
\multicolumn{2}{c}{} \\
wheat, 209 maize, 293 jute, 255 pulses and 211 oilseeds. \\
The exchange rate is USD 1 = BDT 81.86 (BB, 2013) \\
Source: NFPCSP Field Survey, 2012.
\end{tabular}


Table 3. Pesticide use rates and its factor share in gross value of output by farm size categories.

Crops $\%$ of farmers using _ Within pesticide users in each farm size category pesticides Pesticide use rate (BDT Pesticide cost share as $\mathrm{ha}^{-1}$ ) gross value of output (\%)

Marginal farms

74.71
74.89

1025.47

1.33

Small farms

76.50

1124.56

Medium/large farms

75.37

1120.85

All farms

1090.53

1.40

Note: Total number of farms is 2083 comprising of 696 marginal farms, 685 small farms and 702 medium/large farms.

The exchange rate is USD $1=$ BDT $81.86(\mathrm{BB}, 2013)$

Source: NFPCSP Field Survey, 2012. 
Table 4. Definition, measurement and summary statistics of the variables used in the empirical model.

\begin{tabular}{|c|c|c|c|}
\hline \multirow{2}{*}{$\begin{array}{l}\text { Variables } \\
\text { Dependent variable }\end{array}$} & \multirow[t]{2}{*}{ Definition and measurement } & \multicolumn{2}{|c|}{$\begin{array}{r}\text { Mean Standard } \\
\text { Deviation }\end{array}$} \\
\hline & & & \\
\hline Pesticide use rate & BDT ha ${ }^{-1}$ & 821.95 & 897.77 \\
\hline \multicolumn{4}{|l|}{ Output prices } \\
\hline Rice price & BDT $\mathrm{kg}^{-1}$ (Weighted average price of all varieties) & 16.90 & 2.77 \\
\hline Wheat/maize price (weighted) & BDT kg-1 (Weighted average price of wheat and maize) & 17.96 & 1.61 \\
\hline Jute price & BDT kg-1 & 36.96 & 3.93 \\
\hline Pulse price & BDT kg-1 & 48.99 & 2.47 \\
\hline Oilseed price & BDT kg-1 & 47.95 & 1.56 \\
\hline \multicolumn{4}{|l|}{ Input prices } \\
\hline Land rent & $\mathrm{BDT}_{\text {ha }}{ }^{-1}$ (Actual rent value and/or imputed value) & 36.98 & 19.81 \\
\hline Urea price & BDT kg-1 & 14.23 & 3.40 \\
\hline Triple Super Phosphate price & BDT kg-1 & 23.55 & 2.26 \\
\hline Muriate of Potash price & BDT kg-1 & 15.87 & 1.60 \\
\hline Diammonium Phosphate price & BDT kg-1 & 37.90 & 10.01 \\
\hline Gypsum price & BDT kg-1 & 8.75 & 7.15 \\
\hline Labour wage & BDT person day ${ }^{-1}$ & 236.62 & 55.98 \\
\hline \multicolumn{4}{|l|}{ Area cultivated } \\
\hline Rice area & ha & 0.77 & 1.11 \\
\hline Wheat/maize area & ha & 0.14 & 0.40 \\
\hline Jute area & ha & 0.06 & 0.24 \\
\hline Pulse area & ha & 0.04 & 0.15 \\
\hline Oilseed area & ha & 0.06 & 0.25 \\
\hline \multicolumn{4}{|l|}{ Socio-economic characteristics } \\
\hline Average age of the farmer & Years & 44.87 & 12.78 \\
\hline $\begin{array}{l}\text { Average education level of the } \\
\text { farmer }\end{array}$ & Years of completed schooling & 5.59 & 3.92 \\
\hline Average family size & Number of person per household & 5.04 & 1.93 \\
\hline Marginal farms & Dummy $(1=$ if farm size is $50-100$ decimals; $0=$ otherwise $)$ & 0.33 & -- \\
\hline Small farms & Dummy $(1=$ if farm size is $101-250$ decimals; $0=$ otherwise $)$ & 0.34 & -- \\
\hline Medium/large farms & Dummy ( $1=$ if farm size is 251 decimals and above; $0=$ otherwise $)$ & 0.33 & -- \\
\hline
\end{tabular}




\begin{tabular}{|c|c|c|c|}
\hline \multirow{2}{*}{$\begin{array}{l}\text { Variables } \\
\text { Organic manure use rate }\end{array}$} & \multirow{2}{*}{$\begin{array}{l}\text { Definition and measurement } \\
\mathrm{kg} \mathrm{ha}^{-1}\end{array}$} & \multicolumn{2}{|c|}{$\begin{array}{r}\text { Mean Standard } \\
\text { Deviation }\end{array}$} \\
\hline & & 2273.28 & 4462.32 \\
\hline Membership in NGOs & Dummy $(1=$ if member in an NGO; $0=$ otherwise $)$ & 0.12 & -- \\
\hline \multicolumn{4}{|l|}{ Agroecology } \\
\hline $\begin{array}{l}\text { Old Himalayan Piedmont Plain and } \\
\text { Tista Floodplain }\end{array}$ & Dummy ( $1=$ if hptf; $0=$ otherwise $)$ & 0.22 & -- \\
\hline \multicolumn{2}{|c|}{ Karatoya Floodplain and Atrai BasinDummy ( $1=$ if kfab; $0=$ otherwise $)$} & 0.25 & -- \\
\hline Brahmaputra- Jamuna Floodplain & Dummy $(1=$ if bjf; $0=$ otherwise $)$ & 0.20 & -- \\
\hline High Ganges River Floodplain & Dummy ( $1=$ if hgrf; $0=$ otherwise $)$ & 0.10 & -- \\
\hline Low Ganges River Floodplain & Dummy ( $1=$ if lgrf; $0=$ otherwise $)$ & 0.08 & -- \\
\hline Ganges Tidal Floodplain & Dummy ( $1=$ if gtf; $0=$ otherwise $)$ & 0.05 & -- \\
\hline \multicolumn{4}{|l|}{ Floodplain } \\
\hline \multicolumn{4}{|l|}{ Land Elevation } \\
\hline High Land & $\begin{array}{l}\text { Proportion of High Land (i.e., no flooding) in total area of respective } \\
\text { agroecological zone }\end{array}$ & 0.30 & 0.16 \\
\hline Medium High Land & $\begin{array}{l}\text { Proportion of Medium High Land (i.e., flooding depth of } 0.01-0.90 \mathrm{~m} \text { ) in } \\
\text { total area of respective agroecological zone }\end{array}$ & 0.39 & 0.14 \\
\hline Medium Low Land & $\begin{array}{l}\text { Proportion of Medium Low Land (i.e., flooding depth of } 0.91-1.83 \mathrm{~m} \text { ) in } \\
\text { total area of respective agroecological zone }\end{array}$ & 0.16 & 0.08 \\
\hline Low/Very Low Land & $\begin{array}{l}\text { Proportion of Low and/or Very Low Land (i.e., flooding depth of }>1.84 \mathrm{~m} \text { ) } \\
\text { in total area of respective agroecological zone }\end{array}$ & 0.14 & 0.10 \\
\hline \multicolumn{4}{|c|}{ 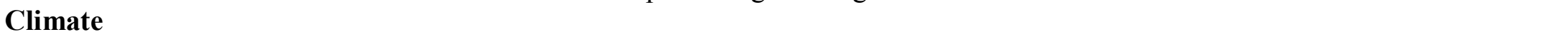 } \\
\hline Total annual rainfall & $\mathrm{mm}$ of total precipitation at the district level & 1707.95 & 992.20 \\
\hline Temperature variability & $\begin{array}{l}\text { Standard deviation of monthly maximum temperature }\left({ }^{0} \mathrm{C}\right) \text { at the district } \\
\text { level }\end{array}$ & 3.96 & 0.55 \\
\hline Number of observations & & 2083 & - \\
\hline
\end{tabular}

(BDT $81.86(\mathrm{BB}, 2013)$

Source: NFPCSP Field Survey, 2012. 


\begin{tabular}{|c|c|c|c|c|}
\hline Test & Parameter restrictions & F-statistic & $\begin{array}{l}\text { Degrees o } \\
\text { freedom } \\
\left(v_{1}, v_{2}\right) \\
\end{array}$ & Decision \\
\hline $\begin{array}{l}\text { The full model with all the } \\
\text { environmental variables is superior to } \\
\text { the model with no environmental } \\
\text { variables }\end{array}$ & $\mathrm{H}_{0}:$ All $\kappa_{\mathrm{i}}=0$ & $\begin{array}{l}376.20 * * * \\
\text { (Likelihood } \\
\text { Ratio test) }\end{array}$ & $\begin{array}{l}9 \\
9(\text { Chi- } \\
\text { square })\end{array}$ & $\begin{array}{l}\text { Reject } \mathrm{H}_{0} \text { : The full model with environmental } \\
\text { variable is superior }\end{array}$ \\
\hline $\begin{array}{l}\text { No influence of output prices on } \\
\text { pesticide use }\end{array}$ & $\mathrm{H}_{0}: \beta_{1}=\beta_{2}=. .=\beta_{5}=0$ & $5.14 * * *$ & $(5,2050)$ & $\begin{array}{l}\text { Reject } \mathrm{H}_{0} \text { : Output prices jointly exert } \\
\text { significant influence on pesticide use }\end{array}$ \\
\hline $\begin{array}{l}\text { No influence of input prices on } \\
\text { pesticide use }\end{array}$ & $\mathrm{H}_{0}: \beta_{6}=\beta_{2}=. .=\beta_{12}=0$ & $9.03 * * *$ & $(7,2050)$ & $\begin{array}{l}\text { Reject } \mathrm{H}_{0} \text { : Input prices jointly exert significant } \\
\text { influence on pesticide use }\end{array}$ \\
\hline $\begin{array}{l}\text { No influence of area cultivated under } \\
\text { different crops on pesticide use }\end{array}$ & $\mathrm{H}_{0}: \gamma_{1}=\gamma_{2}=. .=\gamma_{5}=0$ & $9.66 * * *$ & $(5,2050)$ & $\begin{array}{l}\text { Reject } \mathrm{H}_{0} \text { : Area cultivated under different } \\
\text { crops jointly exert significant influence on } \\
\text { pesticide use }\end{array}$ \\
\hline $\begin{array}{l}\text { No influence of socio-economic } \\
\text { factors on pesticide use }\end{array}$ & $\mathrm{H}_{0}: \delta_{1}=\delta_{2}=. .=\delta_{5}=0$ & $7.79 * * *$ & $(5,2050)$ & $\begin{array}{l}\text { Reject } \mathrm{H}_{0} \text { : Socio-economic characteristics of } \\
\text { the farmers jointly exert significant influence } \\
\text { on pesticide use }\end{array}$ \\
\hline $\begin{array}{l}\text { No influence of farm size categories } \\
\text { on pesticide use }\end{array}$ & $\mathrm{H}_{0}: \delta_{6}=\delta_{7}=0$ & $2.42 * *$ & $(2,2050)$ & $\begin{array}{l}\text { Reject } \mathrm{H}_{0} \text { : Farm size categories jointly exert } \\
\text { significant influence on pesticide use }\end{array}$ \\
\hline $\begin{array}{l}\text { No influence of agroecological } \\
\text { characteristics on pesticide use }\end{array}$ & $\mathrm{H}_{0}: \kappa_{1}=\kappa_{2}=. .=\kappa_{6}=0$ & $62.82 * * *$ & $(6,2050)$ & $\begin{array}{l}\text { Reject } \mathrm{H}_{0} \text { : Agroecological characteristics } \\
\text { jointly exert significant influence on pesticide } \\
\text { use }\end{array}$ \\
\hline $\begin{array}{l}\text { No influence of land elevation on } \\
\text { pesticide use }\end{array}$ & $\mathrm{H}_{0}: \kappa_{7}=0$ & $21.88 * * *$ & $(1,2050)$ & $\begin{array}{l}\text { Reject } \mathrm{H}_{0} \text { : Land elevation significantly } \\
\text { influences pesticide use }\end{array}$ \\
\hline $\begin{array}{l}\text { No influence of climatic factors on } \\
\text { pesticide use }\end{array}$ & $\mathrm{H}_{0}: \kappa_{11}=\kappa_{12}=0$ & $17.87 * * *$ & $(2,2050)$ & $\begin{array}{l}\text { Reject } \mathrm{H}_{0} \text { : Climatic factors jointly exert } \\
\text { significant influence on pesticide use }\end{array}$ \\
\hline
\end{tabular}

Note: $\quad * * *$ Significant at $1 \%$ level $(\mathrm{p}<0.01)$ ** Significant at $5 \%$ level $(\mathrm{p}<0.05)$, 
Table 6. Determinants of pesticide use at the farm level: a multivariate Tobit model.

\begin{tabular}{|c|c|c|c|c|c|}
\hline \multirow[t]{2}{*}{ Variables } & \multicolumn{5}{|c|}{ Dependent variable: Pesticide use rate per ha } \\
\hline & Parameter & Coefficient & t-ratio & Elasticity & t-ratio \\
\hline Constant & $\alpha_{0}$ & $7935.6960 * * *$ & 3.57 & -- & -- \\
\hline \multicolumn{6}{|l|}{ Output prices } \\
\hline Rice price & $\beta_{1}$ & $15.0401 *$ & 1.87 & $0.3812 *$ & 1.86 \\
\hline Wheat/maize price & $\beta_{2}$ & -14.7379 & -1.07 & -0.3970 & -1.07 \\
\hline Jute price & $\beta_{3}$ & 10.4101 & 1.55 & 0.5772 & 1.55 \\
\hline Pulse price & $\beta_{4}$ & $38.0099 * * *$ & 4.25 & $2.7931 * * *$ & 4.20 \\
\hline Oilseed price & $\beta_{5}$ & 2.6621 & 0.19 & 0.1915 & 0.19 \\
\hline \multicolumn{6}{|l|}{ Input prices } \\
\hline Land rent & $\beta_{6}$ & -0.6346 & -0.39 & -0.0352 & -0.39 \\
\hline Urea price & $\beta_{7}$ & $-38.0603^{* * *}$ & -3.42 & $-0.8122 * * *$ & -3.40 \\
\hline Triple Super Phosphate price & $\beta_{8}$ & $74.6290 * * *$ & 5.15 & $2.6365^{* * *}$ & 5.08 \\
\hline Muriate of Potash rice & $\beta_{9}$ & 19.1020 & 1.13 & 0.4548 & 1.12 \\
\hline Diammonium Phosphate price & $\beta_{10}$ & -0.1263 & -0.06 & -0.0072 & -0.06 \\
\hline Gypsum price & $\beta_{11}$ & $-5.7675 * *$ & -2.01 & $-0.0757 * *$ & -2.01 \\
\hline Labour wage & $\beta_{12}$ & $1.4752 * *$ & 1.98 & $0.5236^{* *}$ & 1.98 \\
\hline \multicolumn{6}{|l|}{ Area cultivated } \\
\hline Rice area & $\gamma_{1}$ & 0.0654 & 0.70 & 0.0186 & 0.70 \\
\hline Wheat/maize area & $\gamma_{2}$ & -0.2130 & -0.88 & -0.0114 & -0.88 \\
\hline Jute area & $\gamma_{3}$ & 0.2311 & 0.55 & 0.0051 & 0.55 \\
\hline Pulse area & $\gamma_{4}$ & $-4.8192 * * *$ & -6.71 & $-0.0728 * * *$ & -6.50 \\
\hline Oilseed area & $\gamma_{5}$ & -0.2596 & -0.57 & -0.0053 & -0.57 \\
\hline \multicolumn{6}{|l|}{ Socio-economic characteristics } \\
\hline Age of the farmer & $\delta_{1}$ & 1.2737 & 0.72 & 0.0857 & 0.72 \\
\hline Education level of the farmer & $\delta_{2}$ & $30.2700 * * *$ & 5.50 & $0.2537 * * *$ & 5.40 \\
\hline Family size & $\delta_{3}$ & -6.1009 & -0.50 & -0.0461 & -0.50 \\
\hline Organic manure use rate per ha & $\delta_{4}$ & $0.0154 * * *$ & 2.95 & $0.0524 * * *$ & 2.93 \\
\hline Membership in NGOs & $\delta_{5}$ & -15.8922 & -0.25 & -0.0029 & -0.25 \\
\hline Small farms & $\delta_{6}$ & $100.2944 * *$ & 1.96 & $0.0495 * *$ & 1.96 \\
\hline Medium/large farms & $\delta_{7}$ & $113.6117^{*}$ & 1.86 & $0.0574 *$ & 1.86 \\
\hline
\end{tabular}




\begin{tabular}{|c|c|c|c|c|c|}
\hline \multirow[t]{2}{*}{ Variables } & \multicolumn{5}{|c|}{ Dependent variable: Pesticide use rate per ha } \\
\hline & Parameter & Coefficient & t-ratio & Elasticity & t-ratio \\
\hline \multicolumn{6}{|l|}{ Agroecology } \\
\hline Old Himalayan Piedmont Plain and Tista Floodplain & $\kappa_{1}$ & $-7560.3280 * * *$ & -5.60 & $-2.4771 * * *$ & -5.52 \\
\hline Karatoya Floodplain and Atrai Basin & $\kappa_{2}$ & $-9047.4870 * * *$ & -5.90 & $-3.3748 * * *$ & -5.81 \\
\hline Brahmaputra Jamuna Floodplain & $\kappa_{3}$ & $-8075.6250 * * *$ & -5.64 & $-2.4424 * * *$ & -5.56 \\
\hline High Ganges River Floodplain & $\kappa_{4}$ & $-6967.1540 * * *$ & -4.83 & $-1.0536 * * *$ & -4.78 \\
\hline Low Ganges River Floodplain & $\kappa_{5}$ & $-9109.6490 * * *$ & -6.09 & $-1.0824 * * *$ & -5.99 \\
\hline Ganges Tidal Floodplain & $\kappa_{6}$ & $-9108.1300 * * *$ & -5.96 & $-0.6887 * * *$ & -5.86 \\
\hline \multicolumn{6}{|l|}{ Land elevation } \\
\hline Medium High Land & $\kappa_{7}$ & $1936.3550 * * *$ & 4.68 & $1.1302 * * *$ & 4.63 \\
\hline High Land ${ }^{\mathrm{a}}$ & $\kappa_{8}$ & $(-769.3845 * *)$ & -1.96 & $\left(-0.3431^{* *}\right)$ & -1.96 \\
\hline Medium Low Land ${ }^{\mathrm{a}}$ & $\kappa_{9}$ & $(-1344.8210)$ & -1.52 & $(-0.3190)$ & -1.52 \\
\hline Low/Very Low Land ${ }^{\mathrm{a}}$ & $\kappa_{10}$ & $(-11415.5800 * * *)$ & -8.58 & $(-2.4069 * * *)$ & -8.19 \\
\hline \multicolumn{6}{|l|}{ Climate } \\
\hline Total annual rainfall & $\kappa_{11}$ & $-2.6474 * * *$ & -5.85 & $-6.7823 * * *$ & -5.76 \\
\hline Variability in maximum average temperature & $\kappa_{12}$ & -125.7742 & -1.05 & -0.7469 & -1.05 \\
\hline \multicolumn{6}{|l|}{ Model diagnostics } \\
\hline \multicolumn{2}{|l|}{ Log-likelihood } & -13312.87 & & & \\
\hline \multicolumn{2}{|l|}{ Chi-square statistic (33 df) } & $822.96 * * *$ & & & \\
\hline \multicolumn{2}{|l|}{ Left censored observations } & 513 & & & \\
\hline \multicolumn{2}{|l|}{ Uncensored observations } & 1570 & & & \\
\hline \multicolumn{2}{|l|}{ Total number of observations } & 2083 & & & \\
\hline \multicolumn{2}{|l|}{ Note: } & type variable each tim & der $\mathrm{t}$ & d high multi & amongst \\
\hline
\end{tabular}


Table A1. Recommended doses of major pesticides used in different crops in Bangladesh

\begin{tabular}{|c|c|c|c|c|c|c|}
\hline Crops & $\begin{array}{l}\text { Name of } \\
\text { Insecticides }\end{array}$ & Generic name & $\begin{array}{c}\text { Recommended } \\
\text { dose per ha }\end{array}$ & $\begin{array}{r}\text { Market price } \\
(\text { BDT per } \\
100 \mathrm{gm} / \mathrm{ml} \text { ) }\end{array}$ & Remarks & $\begin{array}{r}\text { Estimated value of } \\
\text { recommended } \\
\text { dose of pesticide } \\
\text { use per ha (BDT } \\
\left.\text { ha }^{-1}\right) \\
\end{array}$ \\
\hline Rice & Furadan $5 \mathrm{G}$ & Carbofuran & $16.8 \mathrm{~kg}$ & 15 & Generally used 2 times & 2520.00 \\
\hline (Boro/Aman & Sevin $75 \mathrm{WP}$ & Carbaryl & $1000 \mathrm{gm}$ & 100 & & 1000.00 \\
\hline /Aromatic) & Dursban 25EC & Chlorpyriphos & $1000 \mathrm{ml}$ & 120 & & 1200.00 \\
\hline & Ripcord 10EC & Cypermethrin & $500 \mathrm{ml}$ & 130 & & 650.00 \\
\hline & Marshall 20EC & Carbosulfan & $1000-1500 \mathrm{ml}$ & 100 & & 1500.00 \\
\hline Jute & Ripcord 10EC & Cypermethrin & $500 \mathrm{ml}$ & 100 & Generally used $2-3$ times & 650.00 \\
\hline & Dursban 25EC & Chlorpyriphos & $1000 \mathrm{ml}$ & 120 & & 1200.00 \\
\hline & Marshall 20EC & Carbosulfan & $1000-1500 \mathrm{ml}$ & 100 & & 1500.00 \\
\hline Mustard & Malathion 57EC or & Malathion & $1000 \mathrm{ml}$ & 100 & When attacked by Aphid & 1000.00 \\
\hline & Ripcord 10EC & Cypermethrin & $500 \mathrm{ml}$ & 130 & & $650 .($ \\
\hline Maize & Dursban $25 \mathrm{EC}$ or & Chlorpyriphos & $1000 \mathrm{ml}$ & 120 & When attacked by stem borer & 1200.00 \\
\hline & Ripcord $10 \mathrm{EC}$ or & Cypermethrin & $500 \mathrm{ml}$ & 130 & & 650.00 \\
\hline & Marshall 20EC & Carbosulfan & $1000-1500 \mathrm{ml}$ & 100 & & 1500.00 \\
\hline Wheat & Ripcord 10EC & Cypermethrin & $500 \mathrm{ml}$ & 130 & Generally not applied. Applied & 650.0 \\
\hline & Marshall 20EC & Carbosulfan & $1000-1500 \mathrm{ml}$ & 100 & only if there is a need. & 1500.00 \\
\hline Pulse & Ripcord 10EC & Cypermethrin & $500 \mathrm{ml}$ & 130 & Generally not applied. Applied & 650.00 \\
\hline & Dursban 25EC & Chlorpyriphos & $1000 \mathrm{ml}$ & 120 & only if there is a need. & 1200.00 \\
\hline
\end{tabular}

Note: Generally 500 litres of water is required to spray for every one hectare land. It is also important to note that farmers do not apply all pesticides listed within each crop. In general, only one of the pesticides will be applied to control pests or insects. Multiple pesticides will be used only in case of serious outbreak.

Source: Prepared with personal consultation with an entomologist (Professor Md. Abdul Latif) of the Department of Entomology, Sher-e-Bangla Agricultural University, Dhaka, Bangladesh. 